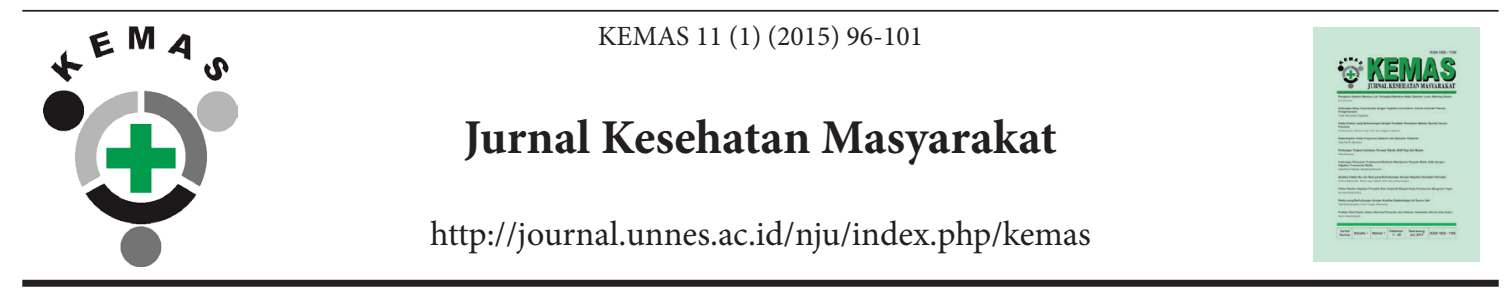

\title{
DUKUNGAN KELUARGA DAN TOKOH MASYARAKAT TERHADAP KEAKTIFAN PENDUDUK KE POSBINDU PENYAKIT TIDAK MENULAR
}

\author{
Haniek Try Umayana, Widya Hary Cahyati ${ }^{凶}$ \\ Jurusan Ilmu Kesehatan Masyarakat Universitas Negeri Semarang, Jawa Tengah
}

\begin{tabular}{l} 
Info Artikel \\
\hline Sejarah Artikel: \\
Diterima 22 April 2015 \\
Disetujui 30 Juni 2015 \\
Dipublikasikan Juli 2015 \\
\hline Keywords: \\
Inhabitants actively; \\
Non communica- \\
ble disease; Posbindu \\
\hline DOI \\
http://dx.doi.org/10.15294/ \\
kemas.v11i1.3521
\end{tabular}

\begin{abstract}
Abstrak
Jumlah posbindu PTM di Kota Semarang semakin meningkat, tetapi jumlah kunjungannya semakin menurun dari tahun 2012 sebesar 470 orang menjadi 398 orang tahun 2013. Salah satu permasalahan di masyarakat adalah kurangnya dukungan dan kepedulian dari anggota keluarga dan tokoh masyarakat terhadap pemeriksaan kesehatan secara rutin yang berdampak pada tingkat kunjungan masyarakat ke posbindu PTM. Tujuan dari penelitian ini untuk mengetahui hubungan antara dukungan keluarga dan dukungan tokoh masyarakat dengan keaktifan penduduk ke kegiatan posbindu PTM di Kota Semarang. Desain penelitian pada tahun 2014 ini menggunakan metode analitik observasional dengan pendekatan cross sectional study. Sampel berjumlah 258 orang yang diambil dengan teknik purposive sampling. Analisis data menggunakan analisis univariat dan analisis bivariat (chi square test dengan $\alpha=0,05$ ). Hasil penelitian menunjukkan bahwa faktor dukungan keluarga ( $\mathrm{p}$ value $=0,0001$ ) dan dukungan tokoh masyarakat ( $\mathrm{p}$ value $=0,001$ ) berhubungan dengan keaktifan penduduk ke kegiatan posbindu PTM di Kota Semarang. Simpulan dari hasil penelitian bahwa ada hubungan antara dukungan keluarga dan dukungan tokoh masyarakat dengan keaktifan penduduk ke kegiatan posbindu PTM di Kota Semarang.
\end{abstract}

\section{FAMILY AND COMMUNITY LEADERS SUPPORT AGAINST INHABITANTS ACTIVELY LIVELINESS TO NON-COMMUNICABLE DISEASE POSBINDU}

\begin{abstract}
The number of posbindu NCD in Semarang City is increased, but the number of visits decreased in 2012 from 470 people to 398 people in 2013. A problem that family support and community leader care had less to check their health as a whole, so public visit rate had less. The purpose of the research was to determine associated of family support and community leader support with the actively of inhabitants to posbindu NCD in Semarang City. Study design at 2014 used observational analytical method with cross sectional study approach. The sample totaled by 258 people by purposive sampling. Data analysis was performed using univariate and bivariate (chi square test with $\alpha=0.05$ ). The results showed that family support ( $p$ value $=0.0001$ ) and community leader support ( $p$ value $=0.001$ ) have correlation with the actively of inhabitants to posbindu NCD in Semarang City are. A summary result that there were correlation between family support and community leader support with the actively of inhabitants to posbindu NCD in Semarang City.
\end{abstract}

(C) 2015 Universitas Negeri Semarang

Alamat korespondensi:

ISSN 1858-1196

Jurusan Ilmu Kesehatan Masyarakat Universitas Negeri Semarang Kampus Sekaran

Gunungpati Semarang 50229 Jawa Tengah-Indonesia

Email : widyahary27@gmail.com 


\section{Pendahuluan}

Berubahnya gaya hidup manusia karena adanya urbanisasi, modernisasi, dan globalisasi telah menyebabkan terjadinya peningkatan Penyakit Tidak Menular (PTM). Penyakit tidak menular telah menjadi penyebab utama kematian secara global pada saat ini (Shilton, 2013). Data WHO menunjukkan bahwa sebanyak 57 juta (63\%) angka kematian yang terjadi di dunia dan 36 juta (43\%) angka kesakitan disebabkan oleh Penyakit Tidak Menular. Global status report on NCD World Health Organization (WHO) tahun 2010 melaporkan bahwa $60 \%$ penyebab kematian semua umur di dunia adalah karena PTM dan $4 \%$ meninggal sebelum usia 70 tahun. Seluruh kematian akibat PTM terjadi pada orang-orang berusia kurang dari 60 tahun, 29\% di negaranegara berkembang, sedangkan di negaranegara maju sebesar 13\% (Remais, 2012).

Proporsi penyakit menular telah menurun sepertiganya dari $44,2 \%$ menjadi $28,1 \%$. Namun, proporsi penyakit tidak menular mengalami peningkatan cukup tinggi dari 41,7\% menjadi 59,5\%. Kasus tertinggi penyakit tidak menular di Jawa Tengah adalah kelompok penyakit jantung dan pembuluh darah sebesar $66,51 \%$ atau sebanyak 806.208 kasus meningkat dibandingkan tahun 2011 sebesar $62,43 \%$ atau sebanyak 773.315 kasus. Peningkatan PTM juga terjadi di Kota Semarang dimana tahun 2010 sebesar 907 kasus, tahun 2011 sebesar 1.077 kasus, tahun 2012 sebesar 2.084 kasus, dan tahun 2013 sebesar 2.725 kasus (DKK Semarang, 2014).

Organisasi kesehatan dunia (WHO) telah merekomendasikan agar memusatkan penanggulangan PTM melalui tiga komponen utama, yaitu surveilans faktor risiko, promosi kesehatan, dan pencegahan melalui inovasi dan reformasi manajemen pelayanan kesehatan. Pengendalian PTM di Indonesia terdapat dalam UU RI No.36 tahun 2009 tentang penyakit tidak menularyang berisi upaya yang dilakukan dalam pengendalian penyakit tidak menular, yaitu pencegahan, pengendalian, penanganan, dan akibat yang ditimbulkan dari suatu penyakit. Upaya ini dimaksudkan untuk meningkatkan pengetahuan, kesadaran masyarakat, kemauan berperilaku sehat, dan mencegah terjadinya PTM beserta komplikasinya. Salah satu upaya mengendalikan faktor risiko penyakit tidak menular melalui sebuah wadah yang disebut dengan Posbindu PTM (Pos Pembinaan Terpadu Penyakit Tidak Menular). Posbindu PTM merupakan suatu bentuk pelayanan yang melibatkan peran serta masyarakat melalui upaya promotif-preventif untuk mendeteksi dan mengendalikan secara dini keberadaan faktor risiko PTM secara terpadu (Dinkes Kota Semarang, 2014).

Jumlah kunjungan posbindu PTM di Kota Semarang lebih banyak mengalami penurunan. Hal ini terlihat dari jumlah kunjungan posbindu di Kota Semarang selama 2012 sebanyak 470 orang dan pada tahun 2013 sebanyak 398 orang. Angka kunjungan posbindu di Kota Semarang selama tahun 2013, yaitu bulan Januari sebanyak 119 orang menurun pada bulan Maret sebanyak 96 orang, bulan Mei sebanyak 82 orang, bulan Juli sebanyak 66 orang, dan bulan November mengalami peningkatan menjadi 104 orang, tetapi pada bulan Desember menurun lagi menjadi 88 orang (DKK Semarang, 2014).

Perilaku seseorang berkunjung ke tempat pelayanan kesehatan ditentukan oleh tiga faktor, yaitu faktor predisposisi (antara lain pengetahuan, sikap, kepercayaan, nilai, karakteristik individu), faktor pemungkin (antara lain ketersediaan sarana kesehatan, jarak tempuh, hukum pemerintah, keterampilan terkait kesehatan), dan faktor penguat (antara lain keluarga, teman sebaya, guru, tokoh masyarakat) (Handayani, 2012). Di antara ketiga faktor tersebut, faktor dukungan keluarga dan dukungan tokoh masyarakat sangat penting karena sebagai faktor penguat dari perilaku seseorang. Menurut Trihardini (2007), perilaku mengikuti posbindu PTM sangat efektif bila didukung oleh situasi sosial yang baik. Keluarga, teman dekat, teman kerja, dan lingkungan sekitar merupakan komponen penting dari terbentuknya perilaku seseorang dalam mengikuti pelayanan kesehatan dalam posbindu PTM.

Dukungan keluarga dapat memperkuat setiap individu, menciptakan kekuatan keluarga, memperbesar penghargaan terhadap diri sendiri, mempunyai potensi sebagai strategi pencegahan yang utama bagi seluruh keluarga dalam menghadapi tantangan 
kehidupan sehari-hari serta mempunyai relevansi dalam masyarakat yang berada dalam lingkungan yang penuh dengan tekanan. Salah satu permasalahan yang dihadapi masyarakat antara lain adalah kurangnya dukungan dan kepedulian dari anggota keluarga dan masyarakat terhadap pemeriksaan kesehatan secara rutin, sehingga berdampak pada tingkat kunjungan masyarakat ke posbindu PTM. Lingkungan masyarakat merupakan salah satu faktor yang mempengaruhi terhadap pembentukan dan perkembangan perilaku individu, baik lingkungan fisik maupun lingkungan sosio-psikologis, termasuk didalamnya adalah belajar (Pertiwi, 2013). Tujuan penelitian ini adalah untuk mengetahui hubungan antara dukungan keluarga dan dukungan tokoh masyarakat dengan keaktifan penduduk pada kegiatan posbindu PTM di Kota Semarang.

\section{Metode}

Desain penelitian ini menggunakan metode survei analitik dengan pendekatan cross sectional study, yaitu penelitian untuk mempelajari dinamika korelasi antara faktor risiko dengan efek, dengan cara pendekatan, observasi, atau pengumpulan data sekaligus pada suatu saat. Populasi dalam penelitian ini adalah seluruh anggota posbindu di Kota Semarang tahun 2014 dengan usia $\geq 25$ tahun yang aktif dan tidak aktif datang ke posbindu PTM yang berjumlah 580 orang. Sampel penelitian sebanyak 258 orang yang diambil dengan teknik purposive sampling.

Instrumen penelitian menggunakan kuesioner. Analisis data yang digunakan adalah analisis univariat dengan menggambarkan frekuensi dan distribusi dari variabel penelitian, yaitu dukungan keluarga dan dukungan tokoh masyarakat, dan keaktifan penduduk dalam kegiatan posbindu PTM. Analisis bivariat dilakukan menggunakan uji chi square $(\alpha=$ $0,05)$ dan perhitungan dari nilai PR (Prevalence Ratio).

\section{Hasil dan Pembahasan}

Berdasarkan hasil penelitian, diperoleh data distribusi responden berdasarkan dukungan keluarga, dukungan tokoh masyarakat, dan keaktifan penduduk dapat dilihat pada tabel 1, sebagai berikut:

Berdasarkan hasil penelitian, diperoleh data distribusi responden berdasarkan dukungan keluarga dapat dilihat pada tabel 1 , diketahui bahwa responden dengan dukungan keluarga baik (65,9\%), dukungan keluarga $(26,4 \%)$, dan dukungan keluarga kurang $(7,8 \%)$. Hasil ini menunjukkan bahwa dukungan keluarga pada kegiatan posbindu PTM sebagian besar baik. Dukungan keluarga kategori kurang dan cukup jika digabungkan memiliki jumlah responden masih lebih sedikit dibandingkan dukungan keluarga kategori baik.

Berdasarkan hasil penelitian, diperoleh data distribusi responden berdasarkan dukungan tokoh masyarakat dapat dilihat pada tabel 1, diketahui bahwa responden dengan

Tabel 1. Distribusi Responden Berdasarkan Dukungan Keluarga, Dukungan Tokoh Masyarakat, dan Keaktifan Penduduk

\begin{tabular}{cccc}
\hline Variabel & Kategori & Frekuensi & Presentase (\%) \\
\hline \multirow{3}{*}{ Dukungan Keluarga } & Kurang & 20 & 7,8 \\
& Cukup & 68 & 26,4 \\
& Baik & 170 & 65,9 \\
& Jumlah & 258 & 100,0 \\
& Kurang & 20 & 7,8 \\
Dukungan Tokoh Masyarakat & Cukup & 47 & 18,2 \\
& Baik & 191 & 74,0 \\
& Jumlah & 258 & 100,0 \\
\multirow{2}{*}{ Keaktifan Penduduk } & Tidak Aktif & 135 & 52,3 \\
& Aktif & 123 & 47,7 \\
\hline
\end{tabular}

Sumber : Data Primer 
Tabel 2. Hubungan antara Dukungan Keluarga dengan Keaktifan Penduduk ke Posbindu PTM

\begin{tabular}{|c|c|c|c|c|c|c|c|c|}
\hline \multirow{3}{*}{\multicolumn{2}{|c|}{ Variabel }} & \multirow{3}{*}{ Kategori } & \multicolumn{4}{|c|}{ Keaktifan Posbindu PTM } & \multirow{3}{*}{$P$ value } & \multirow{3}{*}{ PR } \\
\hline & & & \multicolumn{2}{|c|}{ Tidak Aktif } & \multicolumn{2}{|c|}{ Aktif } & & \\
\hline & & & $\mathbf{n}$ & $\%$ & $\mathbf{n}$ & $\%$ & & \\
\hline \multirow{3}{*}{\multicolumn{2}{|c|}{ Dukungan Keluraga }} & Kurang+Cukup & 71 & 80,7 & 17 & 19,3 & \multirow{3}{*}{0,0001} & \multirow{3}{*}{2,13} \\
\hline & & Baik & 64 & 37,6 & 106 & 62,4 & & \\
\hline & & Jumlah & 135 & 52,3 & 123 & 47,7 & & \\
\hline \multirow{3}{*}{\multicolumn{2}{|c|}{$\begin{array}{l}\text { Dukungan } \\
\text { Masyarakat }\end{array}$}} & Kurang+Cukup & 64 & 82,1 & 14 & 17,9 & \multirow{3}{*}{0,001} & \multirow{3}{*}{1,52} \\
\hline & & Baik & 71 & 39,4 & 109 & 60,6 & & \\
\hline & & Jumlah & 135 & 52,3 & 123 & 47,7 & & \\
\hline
\end{tabular}

Sumber : Data Primer

dukungan tokoh masyarakat kategori baik (74\%), dukungan tokoh masyarakat kategori cukup (18,2\%), dan dukungan tokoh masyarakat kategori kurang (7,8\%). Hasil ini menunjukkan bahwa dukungan tokoh masyarakat pada kegiatan posbindu PTM sebagian besar baik. Dukungan tokoh masyarakat kategori kurang dan cukup jika digabungkan memiliki jumlah responden masih lebih sedikit dibandingkan dukungan tokoh masyarakat kategori baik.

Berdasarkan hasil penelitian, diperoleh data distribusi responden berdasarkan keaktifan penduduk dapat dilihat pada tabel 1, diketahui bahwa responden yang tidak aktif sebanyak 135 orang $(52,3 \%)$ dan responden yang aktif sebanyak 123 orang (7,8\%). Hasil ini menunjukkan bahwa keaktifan penduduk kategori aktif pada kegiatan posbindu PTM memiliki responden yang lebih sedikit. Keaktifan penduduk kategori tidak aktif pada kegiatan posbindu PTM memiliki responden yang lebih banyak.

Berdasarkan analisis bivariat diperoleh tabulasi silang antara variabel dukungan keluarga dan dukungan tokoh masyarakat dengan keaktifan penduduk pada kegiatan posbindu PTM di Kota Semarang pada tabel 2, sebagai berikut:

Dukungan keluarga dalam penelitian ini dibagi menjadi tiga kategori, yaitu kurang, cukup, dan baik yang dinilai dari hasil pengisian kuesioner oleh responden. Agar dapat memenuhi syarat uji chi square, maka dilakukan penggabungan sel menjadi bentuk tabel 2x2. Dukungan keluarga kategori kurang dan cukup dilakukan penggabungan karena jumlah responden lebih sedikit dibandingkan dengan dukungan keluarga kategori baik yang jumlah respondennya lebih banyak. Selain itu, dukungan keluarga kategori kurang dan cukup memiliki akibat lebih kecil terhadap tidak aktifnya penduduk pada kegiatan posbindu PTM dibandingkan dengan dukungan keluarga kategori baik.

Hasil tabulasi silang antara dukungan keluarga dengan keaktifan penduduk pada kegiatan posbindu PTM di Kota Semarang pada tabel 2, menunjukkan bahwa dukungan keluarga kategori kurang dan cukup lebih banyak yang tidak aktif pada kegiatan posbindu PTM (80,7\%). Dukungan keluarga kategori baik lebih banyak yang aktif pada kegiatan posbindu PTM (62,4\%). Penelitian ini menunjukkan bahwa dukungan keluarga yang baik semakin meningkatkan keaktifan penduduk ke posbindu PTM sebaliknya, dukungan keluarga yang kurang dapat menurunkan keaktifan penduduk ke posbindu PTM. Peran Keluarga juga dapat meningkatkan informasi pada penduduk tentang pentingnya posbindu, sehingga anggota keluarga lain juga dapat berpartisipasi dalam pemeriksaan kesehatan di posbindu PTM secara rutin (Lestari, 2011).

Keluarga sebagai motivator kuat bagi penduduk untuk mengikuti kegiatan posbindu PTM apabila selalu menyediakan diri untuk mendampingi, mengantar atau mengingatkan jadwal posbindu PTM. Keberadaan anggota keluarga memainkan peranan penting dalam mencegah atau paling tidak menunda orang menderita sakit kronis ke lembaga pelayanan kesehatan. Besarnya keterlibatan dan sifat pelayanan yang diberikan keluarga tergantung pada sumber-sumber ekonomi, struktur keluarga, kualitas hubungan, kebutuhan lainnya dan tenaga yang tersedia (Wetle, 1997 dalam Lestari 2011: 80-81).

Hasil uji chi square $p$ value $=0,0001$ 
$(>0,05)$, yang artinya ada hubungan antara dukungan keluarga dengan keaktifan penduduk pada kegiatan posbindu PTM di Kota Semarang. Hasil ini sesuai dengan penelitian Handayani (2012), didapat nilai $\mathrm{p}=0,0001$ menunjukkan bahwa ada hubungan bermakna dukungan keluarga dengan pemanfaatan posbindu. Hasil ini juga sesuai dengan Sunartyasih (2012) dengan $\mathrm{P}=0,039$ bahwa dukungan sosial/ keluarga berhubungan dengan kehadiran penduduk ke posbindu. Peran keluarga sangat berpengaruh terhadap partisipasi masyarakat, jika anggota keluarga sangat berperan, maka masyarakat akan berpartisipasi sesuai sikap anggota keluarganya (Rufiati, 2011).

Hasil perhitungan diperoleh nilai $\mathrm{PR}$ $=2,13$, artinya penduduk dengan dukungan keluarga yang kurang dan cukup memiliki peluang 2,13 kali untuk tidak aktif pada kegiatan posbindu PTM daripada penduduk dengan dukungan keluarga yang baik pada kegiatan posbindu PTM di Kota Semarang. Sesuai dengan penelitian dengan nilai OR $=4,385$, yang artinya keluarga memiliki pengaruh 4,385 kali terhadap pemanfaatan pelayanan kesehatan. Hasil ini juga sesuai dengan penelitian Lestari (2011) didapatkan $\mathrm{OR}=3,2$, yang artinya peran keluarga 3,2 kali berpengaruh terhadap keaktifan kunjungan penduduk ke pelayanan kesehatan.

Dukungan keluarga sangat berperan dalam mendorong minat atau kesediaan seseorang untuk mengikuti kegiatan posbindu. Kehadiran penduduk dalam posbindu yang rendah dapat dipengaruhi oleh kurangnya dukungan keluarga (Fallen, 2010 dalam Sunartyasih, 2012: 200). Hasil penelitian menunjukkan bahwa dukungan keluarga yang kurang karena kurangnya pengetahuan dari anggota keluarga lain mengenai pelayan kesehatan yang dilakukan oleh keluarganya sendiri. Hal ini sesuai dengan teori bahwa individu membutuhkan dukungan sosial yang salah satunya berasal dari keluarga. Dukungan keluarga yang rendah tersebut disebabkan karena anggota keluarga yang bekerja, sehingga kurang memperhatikan pentingnya pemeriksaan kesehatan dalam upaya pencegahan penyakit (Sunartyasih, 2012).

Dukungan tokoh masyarakat dalam penelitian ini dibagi menjadi tiga kategori, yaitu kurang, cukup, dan baik yang dinilai dari hasil pengisian kuesioner oleh responden. Agar dapat memenuhi syarat uji chi square, maka dilakukan penggabungan sel menjadi bentuk tabel $2 \times 2$. Dukungan tokoh masyarakat kategori kurang dan cukup dilakukan penggabungan karena jumlah responden lebih sedikit dibandingkan dengan dukungan tokoh masyarakat kategori baik yang jumlah respondennya lebih banyak. Selain itu, dukungan tokoh masyarakat kategori kurang dan cukup memiliki akibat lebih kecil terhadap tidak aktifnya penduduk pada kegiatan posbindu PTM dibandingkan dengan dukungan tokoh masyarakat kategori baik.

Berdasarkan analisis bivariat diperoleh tabulasi silang antara variabel dukungan tokoh masyarakat dengan keaktifan penduduk pada kegiatan posbindu PTM di Kota Semarang pada tabel 2, menunjukkan bahwa responden dengan dukungan tokoh masyarat kategori kurang dan cukup lebih banyak yang tidak aktif pada kegiatan posbindu PTM (70,1\%). Dukungan tokoh masyarat kategori baik lebih banyak yang aktif ke posbindu PTM (53,9\%). Penelitian ini menunjukkan bahwa dukungan tokoh masyarakat yang baik dapat meningkatkan keaktifan penduduk ke posbindu PTM sebaliknya, dukungan tokoh masyarakat yang kurang dapat menurunkan keaktifan penduduk ke posbindu PTM (Lestari, 2011).

Hasil uji chi-square diperoleh $p$ value sebesar 0,001 $(<0,05)$, yang artinya ada hubungan antara faktor dukungan tokoh masyarakat dengan keaktifan penduduk pada kegiatan posbindu PTM di Kota Semarang. Hasil penelitian ini sesuai dengan penelitian Sunartyasih (2012) didapatkan $p$ value = 0,039 menunjukkan bahwa dukungan sosial masyarakat berhubungan dengan kehadiran penduduk ke posbindu. Hasil perhitungan diperoleh nilai $P R=1,52$, yang artinya penduduk dengan dukungan tokoh masyarakat yang kurang dan cukup memiliki peluang 1,52 kali kali untuk tidak aktif pada kegiatan posbindu daripada penduduk dengan dukungan tokoh masyarakat yang baik pada kegiatan posbindu PTM.

Hasil penelitian ini sesuai dengan teori Snehandu B. Kar (1983), perilaku kesehatan merupakan fungsi dari dukungan sosial dari 
masyarakat sekitarnya. Berdasarkan pedoman penyelenggaraan posbindu PTM bahwa tokoh masyarakat bertugas menggerakkan masyarakat untuk berpartisipasi secara aktif dan mendukung dengan sumber daya yang dimiliki terhadap penyelenggaraan posbindu PTM. Pimpinan kelompok atau organisasi masyarakat mendukung dan berperan aktif dalam kegiatan posbindu PTM sesuai dengan minat dan misi kelompok atau organisasi tersebut (Dinkes Kota Semarang, 2014).

Program kesehatan yang telah mendapat dukungan dari tokoh masyarakat selanjutnya disosialisasikan kepada masyarakat agar memperoleh dukungan dan partisipasi dari masyarakat. Perilaku kesehatan seseorang ditentukan oleh ada atau tidaknya dukungan mayarakat di sekitarnya. Selain dukungan tokoh masyarakat, dukungan tokoh agama juga mempunyai pengaruh di masyarakat. Selanjutnya, tokoh agama ini dapat menjembatani antara pengelola program kesehatan dengan masyarakat. (Handayani, 2012).

Desa yang memiliki kepala desa dengan selalu memberikan motivasi pada setiap pelaksanaan kegiatan di masyarakat, seperti pada posbindu PTM akan lebih baik dalam keberlangsungan dari kegiatan posbindu PTM tersebut. Namun, desa yang kepala desanya tidak memberikan motivasi sama sekali dari suatu program, seperti posbindu akan sulit program posbindu PTM untuk lebih berkembang. Dukungan motivasi tersebut dapat berupa pemberian tugas yang selalu dimonitor dan disupervisi, selalu mempertimbangkan kemampuan kader sebelum memberi tugas, kebiasaan kepala desa untuk melakukan peninjauan terhadap pelaksanaan kegiatan posbindu PTM tersebut (Sigalingging, 2011).

\section{Penutup}

Berdasarkan hasil penelitian dan pembahasan diperoleh simpulan ada hubungan antara dukungan keluarga ( $p$ value $=0,0001)$ dan dukungan tokoh masyarakat ( $p$ value $=0,001$ ) dengan keaktifan penduduk dalam kegiatan posbindu PTM di Kota Semarang.

\section{Ucapan Terima Kasih}

Ucapan terima kasih kami tunjukkan kepada petugas pemegang program posbindu PTM dari Dinas Kesehatan Provinsi Jawa Tengah, Dinas Kesehatan Kota Semarang, puskesmas, kader kesehatan, dan anggota posbindu se-Kota Semarang.

\section{Daftar Pustaka}

Dinas Kesehatan Kota Semarang. 2014. Laporan Posbindu di Kota Semarang Tahun 2013. Dinkes Kota Semarang, Semarang.

Lestari P., Soeharyo H., \& Kris P. 2011. Beberapa Faktor yang Berperan terhadap Keaktifan Kunjungan Lansia ke Posyandu, Jurnal Media Medika Indonesiana. 45 (2).

Remais JV, Guang Z, dan Guangwei L, 2012, Convergence of Non-communicable and Infectious Diseases in Low and Middle Income Countries, International Journal of Epidemiology. (42):221-227.

Pertiwi, HW., 2013, Faktor-faktor yang Berhubungan dengan Frekuensi Kehadiran Lanjut Usia di Posyandu Lansia, Jurnal Ilmiah Kebidanan, 4 (1).

Rufiati, dkk. Pengaruh Permainan FInd Your Mate Terhadap Peningkatan Pengetahuan Kader Posyandu. Jurnal Kemas 6 (2)

Shilton T., Beatriz C., \& Claire B., 2013, Towards a Global Framework for Capacity Building for Non-communicable Disease Advocacy in Low and Middle Income Countries, Global Health Promotion Journal, 20 (4).

Sunartyasih, R., dan Brigita L., 2012, Hubungan Kendala Pelaksanaan Posbindu dengan Kehadiran Lansia di Posbindu RW 08 Kelurahan Palasari Kecamatan Cibiru Kota Bandung, Jurnal Sains, Teknologi, dan Kesehatan, Universitas Islam Bandung 3 (1).

Trihardini, I, 2007, Potret Buram Pelayanan Kesehatan Lanjut Usia di Indonesia, KESMAS, 1 (5). 